\title{
Dr. Fakhreddin Jamali: Pharmacist, Pharmaceutical Scientist and Mentor
}
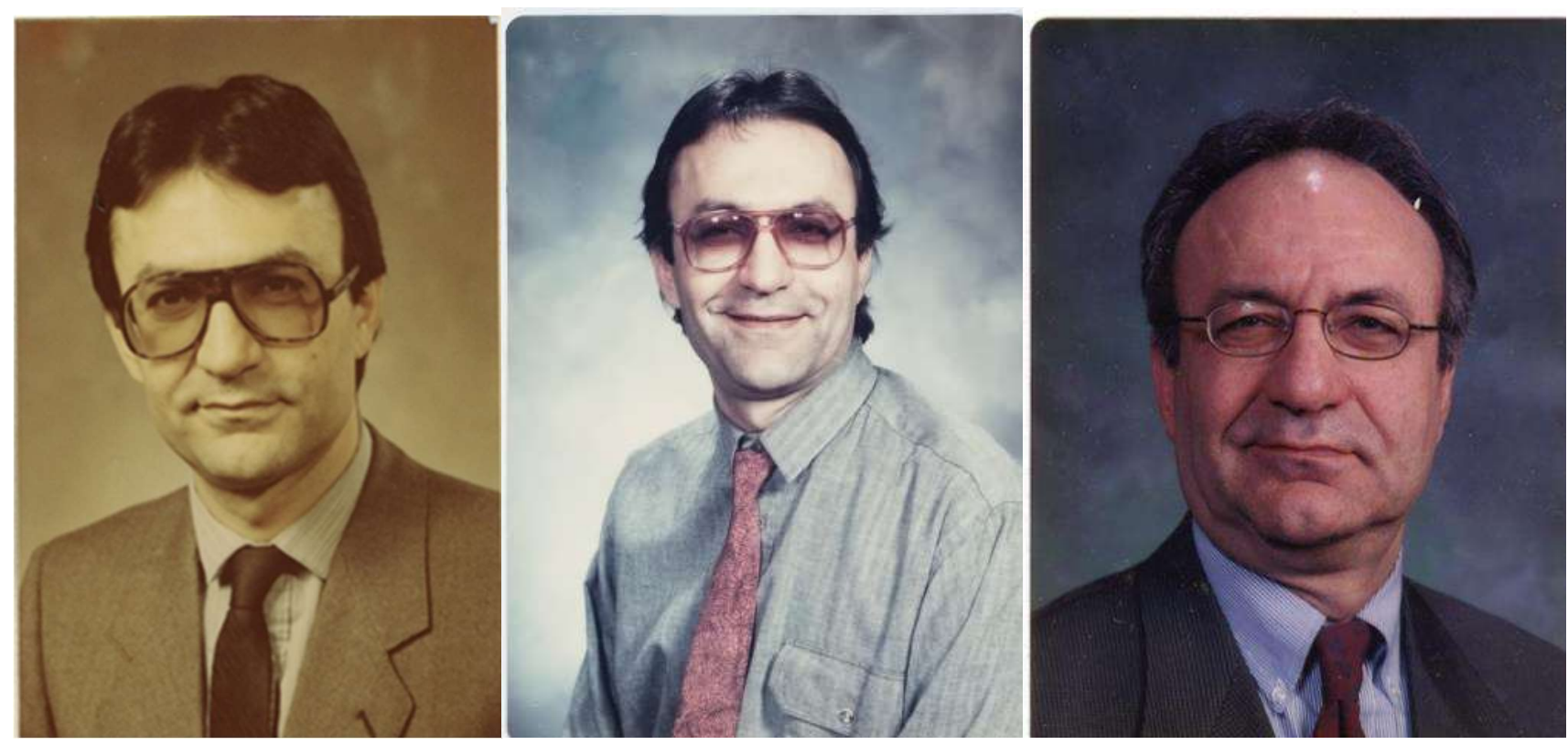

Dr. Fakhreddin "Mo" Jamali is originally from Iran where he received a Doctor of Pharmacy degree from the University of Tehran in 1969. In 1971 he moved to Canada to pursue graduate studies in the Faculty of Pharmaceutical Sciences at the University of British Columbia where he received a master of science in Pharmaceutics (1973) under the direction of Dr. Alan G. Mitchell and a doctorate in Biopharmaceutics \& Pharmacokinetics (1976) under the supervision of Dr. James E. Axelson. He moved back to Iran in 1977 and worked as an assistant professor at the University of Tehran, Faculty of Pharmacy. In 1981 he joined the University of Alberta, Faculty of Pharmacy \& Pharmaceutical Sciences as an Assistant Professor where he has been a Professor since 1989. In 2018 he entered into a three year phased retirement plan. Dr. Jamali also served as Associate Dean from 1999 to 2004. He was a Visiting Professor at the Research Institute for Science and Technology of the Tokyo University of Science from 2010 to 2014. He has also been a principal member of various centres of excellence. Dr. Jamali is married to Dr. Elaheh Keshavarz. They have one son, Vafa.

In 1997, Dr. Jamali was founding President of the Canadian Society for Pharmaceutical Sciences (CSPS), a not-for-profit Society whose membership includes scientists worldwide, involved in all aspects of pharmaceutical sciences with affiliations in academia, industry, and government. In 1998 he founded and became Editor-in-Chief of Journal of Pharmacy \& Pharmaceutical Sciences, the first in the field open access fully electronic peerreviewed international journal. 'The Journal charges fees for neither publishing nor subscription. According to the Journal Citation Reports, the journal had an impact factor of 2.51 during a five year period ending in 2015.

Dr. Jamali is very prolific in his research endeavours. His group was among a handful of laborites worldwide to start applying the principles of stereochemistry in drug action and disposition. In addition, his work in the field of analgesia included the finding that pain and/or its trauma results in reduced absorption of drugs at the time when they are needed most has significantly influenced the industry. In 2002 he founded a spin-off corporation (EquiTech) to commercialize his scientific and discoveries on rapid acting analgesic formulations. Although, his inventions did not come to commercial fruitarian, his idea has been adopted by the main pharmaceutical firms.

Dr. Jamali's group is credited for finding that inflammatory conditions such as arthritis, result in reduced response to some important drugs such as those needed to control blood pressure. This is despite the fact that the bioavailability of these drugs increases by inflammation. Many patients afflicted with arthritis also have high blood pressure. 
With his focus on the general field of action, disposition and toxicity of drugs, he has published numerous refereed articles, mainly with co-authorship of more than 40 trainees. His trainees hold important positions in academia, industry and governments including the editors of this issue of JPPS. The majority of Dr. Jamali's graduate students were members of his undergraduate pharmacokinetics course that he thought through his academic career, which is a testament to his inspiring teaching style.

Dr. Jamali has been invited to speak at many scientific gatherings. He has served as an expert witness, as a consultant or a member of the board of directors of many pharmaceutical houses. He has served on several provincial, national or international expert advisory committees

For his academic achievements and research, he has received the Canadian Society for Pharmaceutical Sciences Award of Leadership in 2001, and the Canadian Arthritis Network Award of Merit in 2004. He was appointed as a Fellow of the American College of Clinical Pharmacology in 1991, the American Association of Pharmaceutical Sciences in 1996, and the Canadian Society for Pharmaceutical Sciences in 2009. He received the McKeen Cattel Memorial Award of the American College of Clinical Pharmacology in 1993, the McNeil Award of the Association of Canadian Faculties of Pharmacy in 1994, the McCalla Professorship of the University of Alberta in 1996, a Killam Professorship in 2005, the Canadian Society for Pharmaceutical Sciences Lifetime Achievement Award in 2016, and the Biruni National Award of Distinguished Scholars from Shahid Beheshti University of Medical Sciences, Iran, in 2015, among many others.

For his service to the public, he has been honoured with the Alberta Centennial Medal of Outstanding Service in 2005 and the Alberta Pharmacy Centennial Award of Distinction in 2011.

Dr. Jamali is also an accomplished landscape painter. He donates his works to be auctioned in charity events sponsored by various organizations such as the Cancer Board and Arthritis Society.

In closing, we would like to thank Dr. Fakhreddin Jamali, for his tutelage of us all over his career and to each of the authors for dedicating their research to the legacy of our mentor and colleague. Dr. Jamali is a pioneer in pharmacokinetics and pharmacodynamics whose contributions to the Faculty of Pharmacy and Pharmaceutical Sciences at the University of Alberta, nationally, and globally are immense.

Neal Davies, Ph.D., R.Ph., Dion Brocks, Pharm.D., Ph.D., and Sherif Mahmoud, Ph.D., RPh

\section{Guest Editors}

